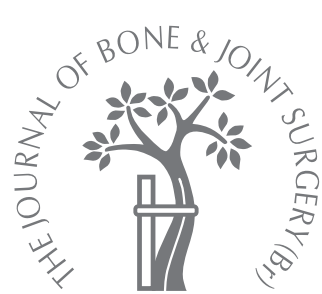

Y.-H. Kim,

D.-Y. Kim, J.-S. Kim

From The Joint Replacement Center of Korea, Ewha Womans University College of Medicine, Seoul, Korea

\title{
Simultaneous mobile- and fixed-bearing total knee replacement in the same patients
}

\author{
A PROSPECTIVE COMPARISON OF MID-TERM OUTCOMES USING \\ A SIMILAR DESIGN OF PROSTHESIS
}

Y.-H. Kim, MD, Professor and Director

D.-Y. Kim, MD, Clinical Fellow J.-S. Kim, MD, Associate Professor

The Joint Replacement Center of Korea

Ewha Womans University DongDaeMun Hospital 70

ChongRo 6-Ga, ChongRo-Gu, Seoul (110-783), Korea.

Correspondence should be sent to Professor Y.-H. Kim; e-mail: younghookim@ewha.ac.kr

(C2007 British Editorial Society of Bone and Joint Surgery doi:10.1302/0301-620X.89B7. $18635 \$ 2.00$

$J$ Bone Joint Surg $[\mathrm{Br}]$ 2007;89-B:904-10.

Received 20 September 2006;

Accepted after revision 7

February 2007

\begin{abstract}
We conducted a randomised prospective study to evaluate the clinical and radiological results of a mobile- and fixed-bearing total knee replacement of similar design in 174 patients who had bilateral simultaneous knee replacement. The mean follow-up was for $\mathbf{5 . 6}$ years (5.2 to 6.1).

The total knee score, pain score, functional score and range of movement were not statistically different $(p>0.05)$ between the two groups. Osteolysis was not seen in any knee in either group. Two knees $(1 \%)$ in the mobile-bearing group required revision because of infection; none in the fixed-bearing group needed revision. Excellent results can be achieved with both mobile- and fixed-bearing prostheses of similar design at mid-term follow-up. We could demonstrate no significant clinical advantage for a mobile bearing.
\end{abstract}

Total knee replacements (TKRs) using welldesigned, fixed-bearing prostheses have produced good long-term results. ${ }^{1-3}$ However, problems with polyethylene wear, osteolysis and failure of fixation have occurred with some fixed-bearing designs. ${ }^{4-8}$ Mobile-bearing total knee prostheses were designed to provide dual-surface articulation at both the upper and lower surfaces of the polyethylene insert. These designs offer the advantage of conformal geometry with a reduction of contact stresses in the polyethylene which may reduce wear. ${ }^{9-11}$ It has also been postulated that a mobile bearing would minimise bone-prosthesis stress at the fixation surface of the tibial component. ${ }^{12,13}$

Several authors have compared the results of different types and designs of mobile- and fixed-bearing TKRs in the same or different patient groups. ${ }^{14-17}$ They report no or negligible differences between the two types of implant as judged either clinically or radiologically. We know of only two studies which have compared the results of mobile- and fixedbearing TKRs using a similar design of prosthesis. ${ }^{16,17}$ The authors found no significant difference between mobile- and fixed- bearings.

We have conducted a randomised prospective study to compare the clinical and radiological results of mobile- and fixed-bearing TKRs which were otherwise of a similar type and design.

\section{Materials and Methods}

Between June 2000 and May 2001, primary bilateral simultaneous TKRs were performed in 194 consecutive patients by the senior author (YHK) under the same anaesthetic, with one side treated immediately after the other. Ten patients were lost to follow-up and ten refused randomisation, leaving 174 patients (348 knees) in the study. Of the ten patients lost to follow-up, seven were not reviewed at one year because of a deterioration in their medical condition, unrelated to knee surgery, and three defaulted two years after operation; their Knee Society ${ }^{18}$ scores had ranged between 90 and 92 points at one year after operation. The study was approved by our institutional review board, and all patients gave informed consent. A press-fit condylar Sigma mobile- or fixed-bearing prosthesis (PFC Sigma, DePuy, Warsaw, Indiana) was used. All implants were of a posterior cruciateretaining design. All the components were cemented. We routinely perform bilateral simultaneous TKRs unless patients have serious medical problems pre-operatively.

The femoral component in both groups is the same and is made of cobalt-chrome. ${ }^{19}$ The cobalt-chrome tibial tray for the mobilebearing PFC Sigma is modular and keelshaped, as is the titanium tibial tray for the 


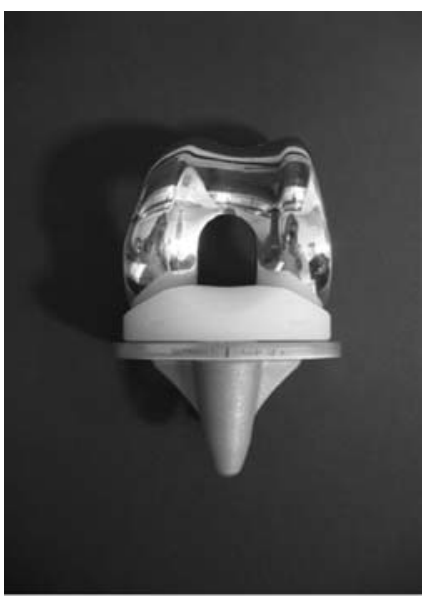

Fig. 1a

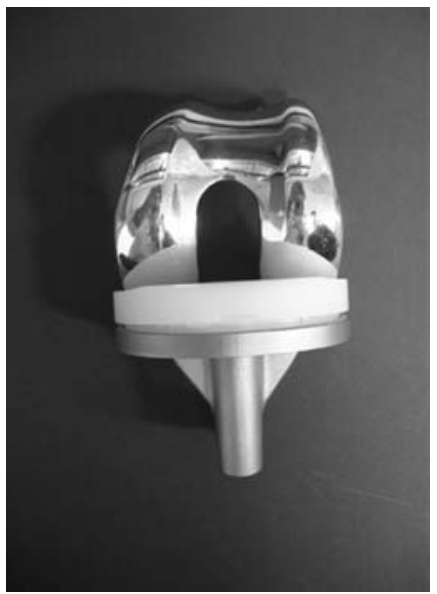

Fig. 1d

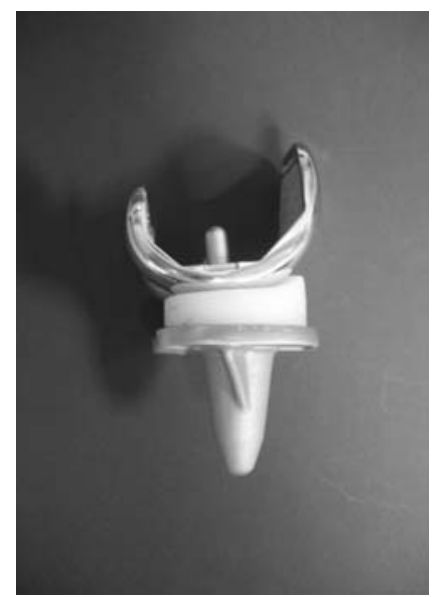

Fig. 1b

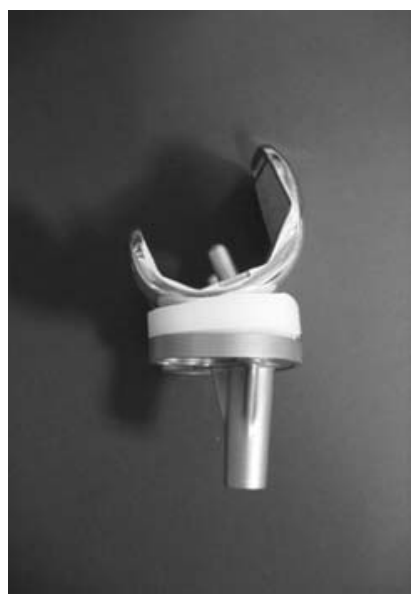

Fig. 1e

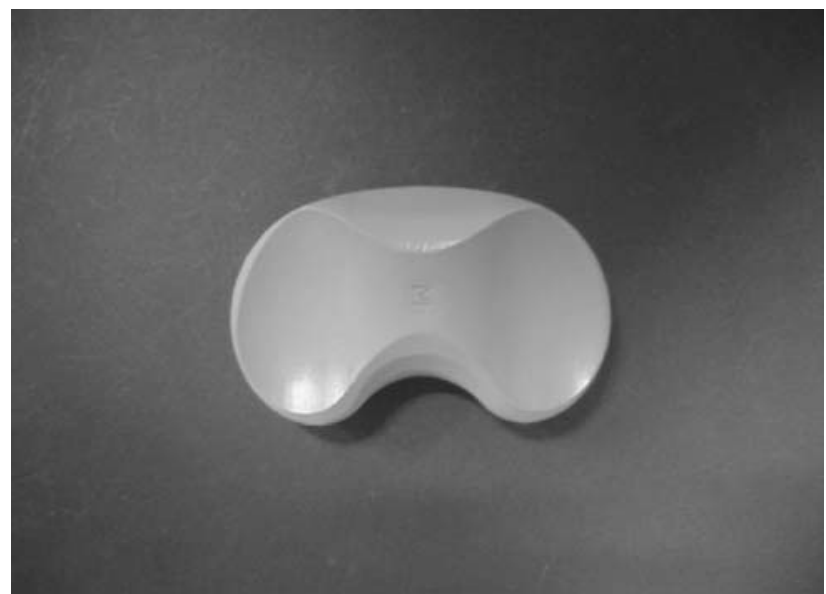

Fig. 1c

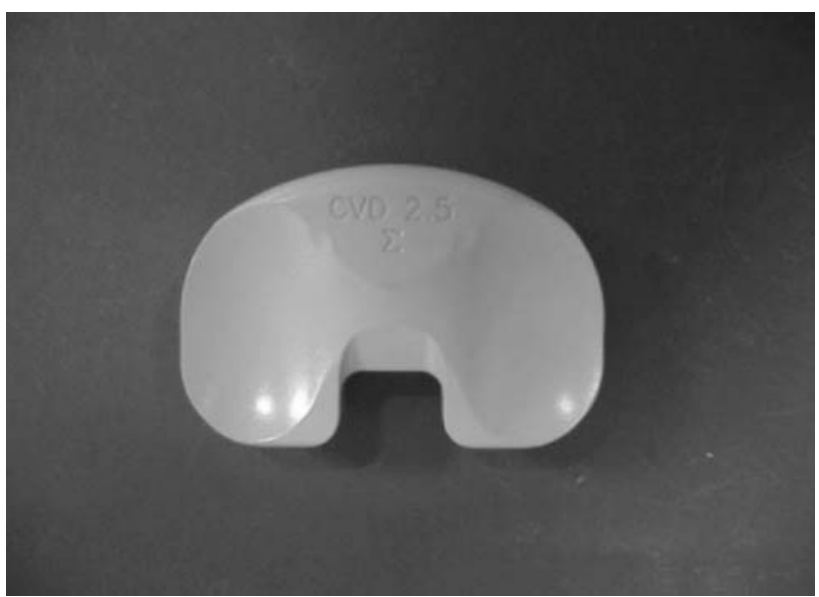

Fig. $1 f$

Photographs of the mobile- and fixed-bearing PFC Sigma total knee prostheses showing a) the anterior view, b) the lateral view and c) the surface of the mobile-bearing prosthesis and d) the anterior view e) the lateral view and f) the surface of the fixed-bearing prosthesis.

fixed-bearing PFC Sigma. The design of the mobile-bearing PFC Sigma is a rotating platform. The fixation surfaces of the tibial tray of both the mobile- and the fixed-bearing PFC Sigma are matt. The articular surface of the tibial tray for the mobile-bearing PFC Sigma is polished, but the upper surface of the fixed-bearing version is matt. Curved tibial inserts were used in all the fixed-bearing knee replacements ${ }^{19}$ (Fig. 1).

Each of the 174 patients received a mobile-bearing TKR on one side and a fixed-bearing TKR on the other. Randomisation of the use of either a mobile- or a fixed-bearing prosthesis was determined from a sequential pool based on a table of randomised numbers. There were 112 women and 62 men with a mean age at the time of the operation of 67 years $(45$ to 85 ). The diagnosis was osteoarthritis in 173 patients (346 knees) and rheumatoid arthritis in one (two knees). No patient had undergone a previous operation. The mean height of the patients was $153.4 \mathrm{~cm}$ (140 to 171$)$ and their mean weight was $62.9 \mathrm{~kg}$ (40 to 85 ).

Surgical technique. The procedure was performed through a midline skin incision (10 to $14 \mathrm{~cm}$ long) with a subvastus approach for all knees. The incision was kept as short as possible and there was no difference in soft-tissue dissection between the two groups. The intact or degenerate anterior cruciate ligament was excised. The status of the posterior cruciate ligament was always evaluated. Recession of the posterior cruciate ligament was required in 30 mobile-bearing knees (17\%) and in 21 fixed-bearing knees $(12 \%)$. In both groups, femoral preparation was done first followed by tibial preparation. Resection of the distal and posterior femoral condyles attempted to remove a thickness of bone equal to that of the femoral component to be implanted.

The ligaments were balanced and the tibial cut aimed to resect $10 \mathrm{~mm}$ of bone, leaving a surface that was perpendic- 
ular to the shaft of the tibia in the coronal plane with a $3^{\circ}$ to $5^{\circ}$ posterior slope in the sagittal plane. In resection of the femur and tibia, care was taken to balance the flexion and extension gaps and to alleviate any flexion contracture. All patellae in both groups were routinely resurfaced using an all-polyethylene prosthesis (DePuy, Warsaw, Indiana).

Splints were applied with the knees in $15^{\circ}$ flexion and were worn for the first 24 hours after the operation. Continuous passive movement was then employed. The settings were advanced incrementally until the knee reached $120^{\circ}$ flexion. All patients began walking with crutches or a walker, and began working on active and passive range of movement exercises on the second day after the operation. Crutches or a walker with full weight-bearing were used for six weeks followed by a cane for a further six weeks.

Patient evaluation. Pre- and post-operative ratings according to the system of the Knee Society ${ }^{18}$ and of the Hospital for Special Surger $y^{20}$ were obtained for all patients. Clinical and radiological evaluations were performed three months and one year after operation and then yearly thereafter. The mean follow-up was 5.6 years (5.2 to 6.1). All clinical data were recorded and compiled by two observers (DYK and another who is not an author) who were not part of the operative team and who had no knowledge of the radiological findings.

Survival analysis was undertaken to determine the cumulative rate of survival of the implant. ${ }^{21}$ The end-point for analysis was revision surgery for any reason, or a recommendation for revision surgery by the senior author.

Radiographs were analysed by one observer (DYK) who had no knowledge of the patient's name. The findings were then recorded by a research assistant (not an author) who knew the patient's identity. Radiographs were obtained before and after surgery including anteroposterior views both standing and supine, a lateral film and a skyline patellar view with $90^{\circ}$ of flexion of the knee. All were taken under fluoroscopic control and were assessed for alignment of the limb, the position of the component, and the presence and location of radiolucent lines at the bone-cement interface, according to the recommendations of the Knee Society. ${ }^{18}$ The skyline patellar views were examined for patellar tilt, subluxation and dislocation.

The level of the joint line was determined in anteroposterior radiographs obtained before and after surgery with the patient supine, by measuring the distance between the tip of the head of the fibula and the distal margin of the lateral femoral condyle pre-operatively, and between the tip of the head of the fibula and the distal margin of the lateral component post-operatively. Any detectable osteolysis around the three components was recorded. All measurements were performed three times for each patient. For angular measurements, the mean interobserver difference was $1.9^{\circ}\left(0.8^{\circ}\right.$ to $\left.2.5^{\circ}\right)$ and the intraclass correlation coefficient was 0.98 (0.96 to 1.00), indicating excellent reproducibility. For metric measurements, the mean interobserver difference was $1.5 \mathrm{~mm}$ (0.8 to 2.1), and the interclass correlation coefficient was 0.99 (0.97 to 1.00).

In order to detect an effect size of 0.5 , corresponding to an anticipated difference of four points and a standard deviation of eight points, with a power of $85 \%$ and a level of significance of $5 \%$, we calculated that 40 participants were required. In anticipation of a small dropout rate, 50 patients were needed for the pilot study. A power analysis of the data was carried out again at the 50-patient mark. We then calculated that 165 patients were required to compare the range of knee movement adequately in both groups. In anticipation of a small dropout rate, we continued to 174 patients.

Statistical comparison of the clinical and radiological results from the two groups was carried out using Student's paired $t$-test, the chi-squared test and the Mantel-Haenszel test. ${ }^{22}$ Values of $\mathrm{p}<0.05$ were considered to be statistically significant.

\section{Results}

The mean operating time in the mobile-bearing group was 67.6 minutes (51 to 95 ) and in the fixed-bearing group was 65.9 minutes ( 48 to 93 ). The mean tourniquet time in the mobile-bearing group was 54.8 minutes (40 to 78 ) and in the fixed-bearing group was 54.3 minutes (45 to 82 ).

The pre-operative and post-operative knee scores, pain scores, walking distance, range of movement, walking support, and ability to negotiate stairs in both groups were not significantly different (Table I). The pre-operative knee scores and functional scores were not statistically different between the fixed- and mobile-bearing knees (Student's paired $t$-test $\mathrm{p}=0.789)$ according to the Knee Society and the Hospital for Special Surgery assessments, neither were they when assessed post-operatively (Student's paired $t$-test $\mathrm{p}=0.490)$.

The difference in pain scores between the fixed- and mobile-bearing knees according to both knee scoring systems was not statistically significant at the latest follow-up (Mantel Haenszel test, $\mathrm{p}=0.949$ ).

The range of movement in fixed- and mobile-bearing knees was not statistically different either before (Student's paired $t$-test $\mathrm{p}=0.875$ ) or after operation (Student's paired $t$-test $\mathrm{p}=0.807$ ) (Table I). Although all knees obtained at least $120^{\circ}$ of flexion passively during the hospital stay, the active range of flexion was reduced to less than $80^{\circ}$ in six patients at the final follow-up.

In the mobile-bearing group, 101 patients $(58 \%)$ were fully satisfied with the outcome of surgery, $65(37 \%)$ were satisfied, and eight $(5 \%)$ were dissatisfied. Of these eight patients, four had constant moderate pain and stiffness and four had an insufficient range of movement to squat. In the fixed-bearing group, 104 patients $(60 \%)$ were fully satisfied, $64(37 \%)$ were satisfied, and six $(3 \%)$ were dissatisfied. Of these six patients, four had constant moderate pain and stiffness, and two had an insufficient range of movement to allow squatting. 
Table I. Clinical results in mobile- and fixed-bearing groups

\begin{tabular}{|c|c|c|c|c|c|c|c|c|}
\hline \multirow[b]{3}{*}{ Parameters } & \multicolumn{4}{|c|}{ Knee Society score } & \multicolumn{4}{|c|}{ Hospital for Special Surgery Knee score } \\
\hline & \multicolumn{2}{|l|}{ Pre-operative } & \multicolumn{2}{|l|}{ Final follow-up } & \multicolumn{2}{|l|}{ Pre-operative } & \multicolumn{2}{|l|}{ Final follow-up } \\
\hline & Mobile & Fixed & Mobile & Fixed & Mobile & Fixed & Mobile & Fixed \\
\hline $\begin{array}{l}\text { Total knee score } \\
\text { (points), mean (range) }\end{array}$ & 28.1 (7 to 36$)$ & 28.7 (2 to 35$)$ & 90 (59 to 100$)$ & 91 (75 to 100$)$ & 41 (15 to 31$)$ & 42 (17 to 33$)$ & $88(69$ to 100$)$ & $89(73$ to 100$)$ \\
\hline $\begin{array}{l}\text { Functional score } \\
\text { (points), mean (range) }\end{array}$ & 25 (5 to 45$)$ & 24 (8 to 38 ) & $83(30$ to 100$)$ & 86 (30 to 100$)$ & - & - & - & - \\
\hline $\begin{array}{l}\text { Pain score (points), } \\
\text { mean (range) }\end{array}$ & $0.3(0$ to 20$)$ & $0.2(0$ to 20$)$ & 48 (30 to 50$)$ & 49 (10 to 50$)$ & 7 (0 to 20$)$ & $7(0$ to 20$)$ & 27 (15 to 30$)$ & 28 (20 to 30$)$ \\
\hline None $(\%)$ & - & - & $132(76)$ & $133(76.5)$ & - & - & $132(76)$ & $135(78)$ \\
\hline Mild (\%) & - & - & $40(23)$ & 41 (23.5) & $3(2)$ & $2(1)$ & $41(23.5)$ & $39(22)$ \\
\hline Moderate (\%) & $3(2)$ & $2(1)$ & $2(1)$ & - & 77 (44) & 78 (45) & $1(0.5)$ & - \\
\hline Severe (\%) & $171(98)$ & $172(99)$ & - & - & $94(54)$ & $94(54)$ & - & - \\
\hline \multicolumn{9}{|l|}{ Walking distance (\%) } \\
\hline Cannot walk & $1(0.5)$ & & - & & $1(0.5)$ & & - & \\
\hline$<1$ block & $110(63)$ & & $24(14)$ & & $110(63)$ & & $24(14)$ & \\
\hline 1 to 5 blocks & $52(30)$ & & $17(9)$ & & $52(30)$ & & $17(9)$ & \\
\hline 5 to 10 blocks & $11(6.5)$ & & $29(17)$ & & $11(6.5)$ & & $29(17)$ & \\
\hline Unlimited & - & & $104(60)$ & & - & & $104(60)$ & \\
\hline $\begin{array}{l}\text { Range of movement } \\
\left({ }^{\circ}\right) \text {, mean (range) }\end{array}$ & 129 (25 to 150$)$ & 128 (20 to 150$)$ & $130(80$ to 140$)$ & 131 (80 to 150$)$ & ) 129 ( 25 to 150$)$ & 128 (20 to 150$)$ & $130(80$ to 140$)$ & 131 (80 to 150$)$ \\
\hline \multicolumn{9}{|l|}{ Walking support (\%) } \\
\hline No support & $101(58)$ & & $154(88.5)$ & & $101(58)$ & & $154(88.5)$ & \\
\hline 1 cane & 68 (39) & & $19(11)$ & & 68 (39) & & $19(11)$ & \\
\hline 1 crutch & - & & - & & - & & - & \\
\hline 2 crutches & $5(3)$ & & $1(0.5)$ & & 5 (3) & & $1(0.5)$ & \\
\hline \multicolumn{9}{|l|}{ Stairs (\%) } \\
\hline Normal & $2(1)$ & & $114(66)$ & & $2(1)$ & & $114(66)$ & \\
\hline With support & $172(99)$ & & $60(34)$ & & 172 (99) & & $60(34)$ & \\
\hline
\end{tabular}

Radiological results. The radiological results in both groups were not significantly different (Table II). All patients had complete radiological follow-up. In both groups there were no significant differences (Student's paired $t$-test $\mathrm{p}>0.05$ ) in the alignment of the knee, the position of the femoral and tibial components in the coronal and sagittal planes, the patellar angles, and the pre- and post-operative joint lines.

There were 21 knees $(12 \%)$ in the mobile-bearing group and $30(17 \%)$ in the fixed-bearing group who had radiolucent lines around the components. This difference was not significant (chi-squared test $\mathrm{p}=0.131$ ). There were 17 of the 21 knees with mobile bearings and 24 of the 30 knees with fixed bearings which had a radiolucent line of $<1 \mathrm{~mm}$ in zone 1 of the tibial plateau. ${ }^{18}$ One knee in the fixedbearing group had a radiolucent line of $<1 \mathrm{~mm}$ in zones 1 and 2 , and one knee in the mobile-bearing group had a radiolucent line $<1 \mathrm{~mm}$ in zone 4 of the tibial plateau. Lateral radiographs showed no tibial radiolucent lines in any zones in any knee. On the femoral side, three knees with mobile bearings and five with fixed bearings had radiolucent lines $<1 \mathrm{~mm}$ in zone 1 of the distal femur. No knee had a radiolucent line in more than two contiguous zones, and no radiolucent lines were observed around the tibial keel or the patellar components. Osteolysis was not seen in any knee in either group (Fig. 2).
Complications. Two knees $(1 \%)$ in the mobile-bearing group became infected. The components were removed and revision undertaken six weeks later. There was no recurrence of infection in either knee. There was no revision of the components in the fixed-bearing group. Another knee $(0.5 \%)$ in the mobile-bearing group sustained a supracondylar fracture after a fall. Open reduction and internal fixation was performed, augmented with fresh-frozen allograft.

One knee $(0.5 \%)$ in each group developed a deep peroneal nerve palsy. This had resolved completely in both within one year of operation.

There were 44 patients $(25 \%)$ in the mobile-bearing group and $52(30 \%)$ in the fixed-bearing group who demonstrated patellofemoral crepitus through the arc of motion. The crepitus was painless and did not limit the patient's ability to negotiate stairs. One of the fixed-bearing knees $(0.5 \%)$ had a patellar clunk, which is a patellofemoral snapping sound, with pain through the arc of $0^{\circ}$ to $30^{\circ}$ flexion of the knee. This resolved following arthroscopic debridement of a fibrous nodule of the quadriceps tendon.

Two knees $(1 \%)$ in each group had a skin-edge necrosis, which was treated with debridement and closure.

The Kaplan-Meier survival ${ }^{21}$ in the best-case scenario revealed $99 \%$ survival of the prosthesis in the mobile-bear- 
ing group and $100 \%$ in the fixed-bearing group at five years (95\% confidence interval (CI) 0.89 to 0.97 ) taking into account all reasons for failure, aseptic loosening and infec- tion. The survival in the worst-case scenario, assuming that those lost to follow-up were failures, revealed $93 \%$ survival

\begin{tabular}{|c|c|c|c|}
\hline Parameters & Mobile group & Fixed group & p-value \\
\hline \multicolumn{4}{|l|}{ Alignment } \\
\hline \multicolumn{4}{|l|}{ Pre-operative } \\
\hline \multicolumn{4}{|l|}{ Varus (knees) (\%) } \\
\hline $0^{\circ}$ to $10^{\circ}$ & $99(57)$ & $94(54)$ & 0.378 \\
\hline $11^{\circ}$ to $20^{\circ}$ & $66(38)$ & $73(42)$ & 0.371 \\
\hline \multicolumn{4}{|l|}{ Valgus (knees) (\%) } \\
\hline $1^{\circ}$ to $10^{\circ}$ & $9(5)$ & $7(4)$ & 0.234 \\
\hline \multicolumn{4}{|l|}{ Final follow-up } \\
\hline \multicolumn{4}{|l|}{ Varus (knees) (\%) } \\
\hline $0^{\circ}$ to $10^{\circ}$ & $2(1)$ & $3(2)$ & 0.381 \\
\hline \multicolumn{4}{|l|}{ Valgus (knees) (\%) } \\
\hline $1^{\circ}$ to $10^{\circ}$ & 172 (99) & $171(98)$ & 0.123 \\
\hline $\begin{array}{l}\text { Mean overall limb alignment at final follow-up } \\
\text { (range) (valgus) }\left(^{\circ}\right)\end{array}$ & 5.4 (-3.8 to 9$)$ & $5.3(-4$ to 7$)$ & 0.7679 \\
\hline \multicolumn{4}{|l|}{$\begin{array}{l}\text { Femoral component position (mean, range) (fem- } \\
\text { oral angle) }\left(\left(^{\circ}\right)\right.\end{array}$} \\
\hline Anteroposterior & 96 (92 to 100$)$ & 96 (92 to 102$)$ & 0.269 \\
\hline Sagittal & $3(-4$ to 10$)$ & $4(-13$ to 14$)$ & 0.218 \\
\hline \multicolumn{4}{|l|}{$\begin{array}{l}\text { Tibial component position (mean, range) (tibial } \\
\text { angle) }\left(\left(^{\circ}\right)\right.\end{array}$} \\
\hline Anteroposterior & 88 (83 to 94$)$ & 89 (81 to 95$)$ & 0.128 \\
\hline Sagittal & 85 (75 to 91$)$ & 86 (75 to 96$)$ & 0.145 \\
\hline \multicolumn{4}{|l|}{$\begin{array}{l}\text { Patellar component angle joint line (mean, } \\
\text { range) }(\mathrm{mm})\end{array}$} \\
\hline Pre-operative & 14.8 (2 to 25$)$ & $14.9(-2.4$ to 26$)$ & 0.788 \\
\hline Final follow-up & 14.7 (4 to 23 ) & 14.6 (3 to 25$)$ & 0.675 \\
\hline \multicolumn{4}{|l|}{ Posterior condylar offset (mean, range) (mm) } \\
\hline Pre-operative & 29.6 (17 to 35$)$ & 27.7 (15 to 34$)$ & 0.744 \\
\hline Final follow-up & 27.9 (18 to 33$)$ & 27.3 (16 to 34$)$ & 0.792 \\
\hline \multicolumn{4}{|l|}{ Radiolucent line (overall) (knees) (\%) } \\
\hline Absence & $158(91)$ & $160(92)$ & \\
\hline Presence & $16(9)$ & $14(8)$ & \\
\hline Radiolucent line (femoral side) (knees) (\%) & & & 0.693 \\
\hline Zone 1 & $4(2.2)$ & $3(2)$ & \\
\hline \multicolumn{4}{|l|}{ Radiolucent line (tibial side) (knees) (\%) } \\
\hline Zone 1 & $12(7)$ & $11(6)$ & \\
\hline Lateral patellar tilt (knees) $(\%)$ & $15(9)$ & $20(11)$ & 0.372 \\
\hline
\end{tabular}

in the mobile-bearing group and $94 \%$ in the fixed-bearing group at five years ( $95 \%$ CI 0.93 to 0.98 ), taking into account all reasons for failure, aseptic loosening and infection.

\section{Discussion}

Mobile-bearing total knee prostheses were designed to reduce contact stresses in the polyethylene with the aim of decreasing wear. ${ }^{9-11}$ O'Connor and Goodfellow ${ }^{12}$ and Goodfellow and $\mathrm{O}^{\prime} \mathrm{Connor}^{13}$ suggested that a mobilebearing design should reduce bone-prosthesis stress at the tibial surface. A number of prosthetic designs are now available, including both mobile- and fixed-bearing surfaces. Despite this, there are few reports comparing the two types.

Kim et $\mathrm{a}^{14}$ prospectively compared the results of AMK fixed-bearing (DePuy) and low contact stress (LCS) meniscal bearing (DePuy) TKRs in 222 patients (444 knees) who had bilateral simultaneous TKR. At a mean follow-up of 7.4 and 10.3 years, respectively, no difference in clinical outcome was identified between the two groups. Woolson and Northrop ${ }^{15}$ compared the results of 45 NexGen fixedbearing (Zimmer, Warsaw, Indiana) and 57 LCS rotating platform (DePuy) prostheses. At a mean follow-up of 41 


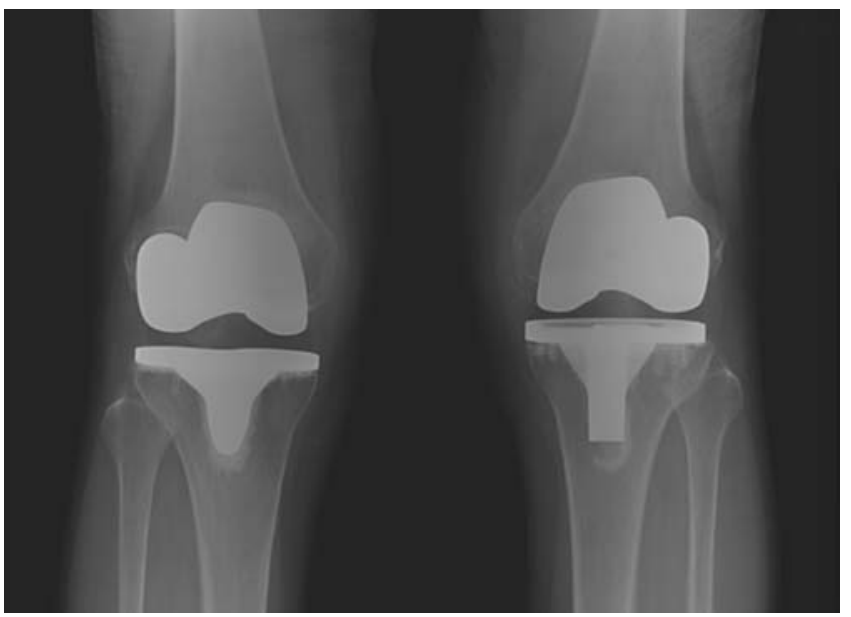

Fig. 2a

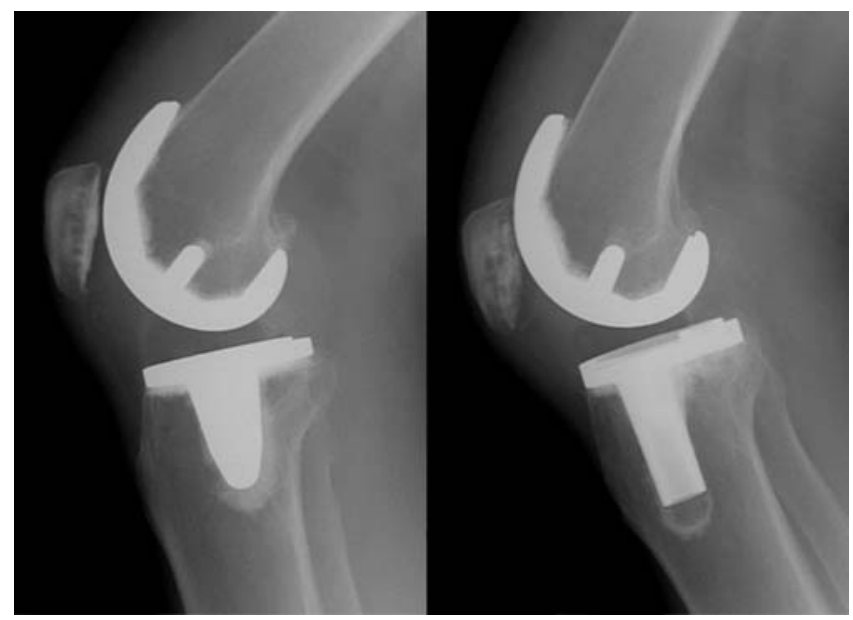

Fig. $2 b$

Post-operative radiographs of a 49-year-old woman who had osteoarthritis of both knees. a) Anteroposterior and b) lateral views with a mobile-bearing in the right knee and a fixed-bearing in the left knee, taken five years post-operatively showing that the femoral, tibial and patellar components in both knees are well fixed in a satisfactory position. There is no radiolucency, detectable wear of the polyethylene tibial bearing, or osteolysis.

months there was no difference between the two groups either clinically or radiologically. However, more patients with a mobile-bearing knee required early revision for failure of the rotating patellar or tibial polyethylene bearings. In all of these previous studies, however, entirely different types and designs of prostheses were compared. This may have affected the clinical outcome.

Two studies ${ }^{16,17}$ compared a similar design of mobileand fixed-bearing prostheses. Price et $\mathrm{al}^{16}$ compared the results of AGC fixed-bearing (Biomet Merck, Bridgend, United Kingdom) and TMK mobile-bearing (Biomet Merck, Darmstadt, Germany) TKRs in 40 patients (80 knees) who had bilateral simultaneous TKR. At one year post-operatively they demonstrated a small but significant clinical advantage for the mobile-bearing design. Wohlrab et $\mathrm{al}^{17}$ compared the NexGen legacy posterior stabilised mobile- and fixed-bearing prostheses (Zimmer) and demonstrated no significant clinical advantages for the mobilebearing design. Our study documented gratifying results of TKRs performed using either a PFC Sigma mobile- or fixedbearing prosthesis. No statistically significant clinical advantage could be demonstrated between a mobile- and a fixed-bearing prosthesis. We focused on good cementing technique using pulsed lavage and cement pressurisation, correct flexion and extension gaps and well balanced ligaments in order to achieve a high success rate at five years. We did not encounter patellar fracture, subluxation or dislocation as complications in either group. This absence of patellar complications may be related partly to the design of the implant ${ }^{19}$ and the subvastus approach used.

Differentiation of the scores between the knees of one individual posed some difficulties. The components of pain, support and range of movement were easily differentiated but the components of distance walked and stair climbing ability were more difficult to differentiate. In these domains, if the patients had difficulties they could always identify the knee that most limited their activities. Despite the patient's active lifestyles, aseptic loosening that necessitated revision was not a notable problem in this series.

Long-term studies of mobile- and fixed-bearing knees have shown no difference in the rate of wear and osteolysis. ${ }^{11,14,23-26}$ However, Collier et $\mathrm{al}^{26}$ found that fixedbearing knees with a grit-blasted tibial baseplate had 2.6 times more osteolysis than those with a polished surface baseplate. Although the results of the current study revealed neither grossly detectable wear of the tibial polyethylene bearing nor peri-prosthetic osteolysis in either group at the time of writing, fixed-bearing TKR using a grit-blasted tibial baseplate will potentially have a higher prevalence of osteolysis in the longer term. The absence of osteolysis in both groups may be related to the small stature and light weight of our patients and the relatively short follow-up.

Buechel and Pappas ${ }^{11}$ and O'Connor and Goodfellow ${ }^{12}$ postulated that the mobile-bearing TKR would minimise bone-prosthesis stress at the tibial surface. In the present study, no knee had a radiolucency in more than three zones around the tibial, femoral or patellar components in either group and we are not able to support the concept that the mobile-bearing prosthesis minimises bone-prosthesis stress at the tibial surface.

The strengths of our study are as follows: we describe one surgeon's experience with a consecutive group of patients in whom simultaneous bilateral TKR was performed, and this minimises confounding factors; apart from the mobility of the tibial polyethylene insert the two 
patterns are of very similar design; this mid-term follow-up of a mean of 5.6 years compares with the longest follow-up in a comparative study of eight years, ${ }^{15,16}$ but our sample size is larger than any previously reported; ${ }^{14,17}$ there was no bias involved in the selection of our patients.

After a mean follow-up of 5.6 years, excellent clinical and radiological results can be achieved with both PFC Sigma mobile- and fixed-bearing cruciate-retaining total knee designs. However, there was no significant clinical advantage for a mobile-bearing over a fixed-bearing TKR.

The authors would like to express their thanks to Sang-Mi Lee (research assistant) for recording all of the data in this study.

No benefits in any form have been received or will be received from a commercial party related directly or indirectly to the subject of this article.

\section{References}

1. Diduch DR, Insall JN, Scott WN, Scuderi GR, Font-Rodriguez D. Total knee replacement in young, active patients: long-term follow-up and functional outcome $J$ Bone Joint Surg [Am] 1997;79-A:575-82.

2. Insall JN, Hood RW, Flawn LB, Sullivan DJ. The total condylar knee prosthesis in gonarthrosis: a five to nine-year follow-up of the first one hundred consecutive replacements. J Bone Joint Surg [Am] 1983;65-A:619-28.

3. Stern SH, Insall JN. Posterior stabilized prosthesis: results after follow-up of nine to twelve years. J Bone Joint Surg [Am] 1992;74-A:980-6.

4. Bugbee WD, Ammeen DJ, Parks NL, Engh GA. 4- to 10-year results with the anatomic modular total knee. Clin Orthop 1998;348:158-65.

5. Colizza WA, Insall JN, Scuderi GR. The posterior stabilized total knee prosthesis: assessment of polyethylene damage and osteolysis after a ten-year-minimum followup. J Bone Joint Surg [Am] 1995;77-A:1713-20.

6. Engh GA. Failure of the polyethylene bearing surface of a total knee replacement within four years: a case report. J Bone Joint Surg [Am] 1988;70-A:1093-6.

7. Schai PA, Thornhill TS, Scott RD. Total knee arthroplasty with the PFC system results at a minimum of ten years and survivorship analysis. J Bone Joint Surg $[\mathrm{Br}]$ 1998;80-B:850-8.

8. Wright TM, Bartel DL. The problem of surface damage in polyethylene total knee components. Clin Orthop 1986;205:67-74.

9. Argenson JN, O'Connor JJ. Polyethylene wear in meniscal knee replacement: a one to nine-year retrieval analysis of the Oxford knee. J Bone Joint Surg [Br] 1992;74B:228-32
10. Bartel DL, Bicknel VL, Wright TM. The effect of conformity, thickness, and material on stresses in ultra-high molecular weight components for total joint replacement. J Bone Joint Surg [Am] 1986;68-A:1041-51.

11. Buechel FF, Pappas MJ. Long-term survivorship analysis of cruciate-sparing versus cruciate-sacrificing knee prostheses using meniscal bearings. Clin Orthop 1990;260:162-9

12. O'Connor JJ, Goodfellow JW. Theory and practice of meniscal knee replacement: designing against wear. Proc Inst Mech Eng 1996;210:217-22.

13. Goodfellow JW, O'Connor J. Clinical results of the Oxford knee: surface arthroplasty of the tibiofemoral joint with a miniscal bearing prosthesis. Clin Orthop 1986;205:21-42.

14. Kim Y-H, Kook H-K, Kim J-S. Comparison of fixed-bearing and mobile-bearing total knee arthroplasties. Clin Orthop 2001;392:101-15.

15. Woolson ST, Northrop GD. Mobile vs fixed-bearing total knee arthroplasty: a clinical and radiologic study. J Arthroplasty 2004;19:135-40.

16. Price AJ, Rees JL, Beard D, et al. A mobile-bearing total knee prosthesis compared with a fixed-bearing prosthesis: a multicenter single-blind randomized controlled trial. J Bone Joint Surg [Br] 2003;85-B:62-7.

17. Wohlrab D, Ditl J, Herrschelmann R, et al. Does the Nexgen LPS flex mobile knee prosthesis offer advantages compared to the Nexgen LPS?: a comparison of clinical and radiographic results. Z Orthop Ihre Grenzgeb 2005;143:567-72 (in German).

18. Insall JN, Dorr LD, Scott RD, Scott WN. Rationale of the Knee Society clinical rating system. Clin Orthop 1989;248:13-14.

19. No authors listed. P.F.C ${ }^{\circledR}$ Sigma knee system. Technical monograph. DePuy, Johnson and Johnson, 2000

20. Insall JN, Ranawat CS, Aglietti P, Shine J. A comparison of four models of total knee replacement prosthesis. J Bone Joint Surg [Am] 1976;58-A:754-65.

21. Kaplan EL, Meier R. Nonparametric estimation from incomplete observations. J Am Statist Assoc 1958;53:457-81

22. Freedman KB, Back S, Bernstein J. Sample size and statistical power of randomized, controlled trials in orthopaedics. J Bone Joint Surg [Br] 2001;83-B:397-402.

23. Jordan LR, Olivo JL, Voorhorst PE. Survivorship analysis of cementless meniscal bearing total knee arthroplasty. Clin Orthop 1997;388:119-23.

24. Ritter MA, Campbell E, Faris PM, Keating EM. Long-term survival analysis of the posterior cruciate condylar total knee arthroplasty: a 10-year evaluation. J Arthroplasty 1989:4:293-6.

25. Scuderi GR, Insall JN. Total knee arthroplasty: current clinical perspectives. Clin Orthop 1992;276:26-32.

26. Collier MB, Engh CA Jr, Mcauley JP, Ginn SD, Engh GA. Osteolysis after total knee arthroplasty: influence of tibial baseplate surface finish and sterilization of polyethylene insert: findings at five to ten years postoperatively. J Bone Joint Surg [Am] 2005;87-A:2702-8 